\title{
Rapid genotype "independent" Zea mays L. (maize) transformation via direct somatic embryogenesis
}

\author{
Keith Lowe ${ }^{1}$ - Mauricio La Rota ${ }^{1} \cdot$ George Hoerster $^{1} \cdot$ Craig Hastings $^{1} \cdot$ Ning Wang $^{1} \cdot$ Mark Chamberlin $^{1} \cdot$ Emily Wu $^{1}$. \\ Todd Jones ${ }^{1} \cdot$ William Gordon-Kamm ${ }^{1}$ (D)
}

Received: 10 January 2018 / Accepted: 26 March 2018 / Published online: 30 April 2018 / Editor: Charles Armstrong

(C) The Author(s) 2018

\begin{abstract}
Constitutive expression of the Zea mays L. (maize) morphogenic transcription factors Baby Boom (Bbm) and Wuschel2 (Wus2) in maize can not only greatly increase transformation efficiency but can also induce phenotypic abnormalities and sterility. In an effort to alleviate the pleiotropic effects of constitutive expression, a genome wide search was undertaken to find suitable maize promoters to drive tissue and timing-specific expression of the transformation enhancing genes $\mathrm{Bbm}$ and Wus2. A promoter from a maize phospholipid transferase protein gene $\left(Z m-P L T P P_{p r o}\right)$ was identified based on its expression in leaves, embryos, and callus while being downregulated in roots, meristems, and reproductive tissues. When $Z m-P L T P_{\text {pro }}$ driving $B b m$ was transformed into immature maize embryos along with a Wus2 expression cassette driven by the nopaline synthase promoter (Nos $\left.{ }_{\text {pro }}:: W u s 2\right)$ abundant somatic embryos rapidly formed on the scutella. These embryos were individual and uniformly transformed and could be directly germinated into plants without a callus phase. Transformed plants could be sent to the greenhouse in as little as 1 mo and regenerated plants matched the seed-derived phenotype for the inbred and were fertile. However, T1 seed from these plants had poor germination. Replacing $N_{\text {pro }}$ with a maize auxin-inducible promoter ( $Z m$-Axigl $1_{p r o}$ ) in combination with $Z m$ $P_{L T P}{ }_{p r o}:: B b m$, allowed healthy, fertile plants to be regenerated. Single-copy T1 seed germinated normally and had a predominantly wild-type inbred phenotype. For maize, this callus-free transformation process has worked in all inbred lines tested.
\end{abstract}

Keywords Maize transformation · Direct embryogenesis $\cdot$ Wuschel $\cdot$ BabyBoom

\section{Introduction}

Since the discovery that immature maize embryos could be used to initiate regenerable embryogenic callus (Green and Phillips 1975), almost all high throughput transformation systems in cereals including maize have required callus formation and selection prior to plant regeneration (see Ji et al. 2013 for review). Immature embryos have been the predominant explant for transformation but some success has been obtained using particle bombardment of alternative explants such as meristems and leaves (Wang et al. 2009). Typically, immature embryos are transformed and embryogenic callus is induced and bulked up under selective pressure to obtain a mass of clonal tissue that can then be regenerated into plants. This

William Gordon-Kamm

william.gordon-kamm@pioneer.com

1 DuPont Pioneer, Johnston, IA, USA process is both labor- and time-intensive taking from 87 to $140 \mathrm{~d}$ from initiation of transformation to sending plants to the greenhouse (Wang 2005; Ishida et al. 2007).

Lowe et al. (2016) have recently described a transformation method that uses the maize transcription factors Baby Boom $(\mathrm{Bbm})$ and Wuschel2 (Wus2) to stimulate the proliferation of transformed cells. In this case, cells were directly induced to form callus by the transgenes rather than transforming cells that had been induced to divide by conventional tissue culture methods. Unfortunately, using this method, pleiotropic effects were observed in transgenic plants making excision of $\mathrm{Bbm}$ and Wus 2 necessary to obtain normal transgenic plants. To alleviate this problem, Lowe et al. (2016) used a desiccation inducible promoter, Rab17 $7_{\text {pro }}$, to control CRE-mediated excision, a method that was compatible with embryogenic callus culture. However, the Lowe et al. (2016) method still required 3 mo of callus selection before transferring callus to dry filter papers for $3 \mathrm{~d}$ to induce excision.

In the present method, described below, somatic embryo formation occurred within the first week after Agrobacterium 
tumefaciens infection, and then the somatic embryos were moved onto medium containing low hormone levels to stimulate further somatic embryo maturation and germination. Within this rapid timeframe, the RAB17 pro was too slow to induce excision and the desiccation treatment was deleterious to the development of small somatic embryos. Thus, another method of controlling WUS and BBM expression was required.

Another approach with the potential to obviate pleiotropic effects of $\mathrm{Bbm}$ and Wus2 was to find promoters that could drive transgene expression in young leaves, embryos, and callus while being off in roots, meristems, and reproductive tissues. A survey of Illumina ${ }^{\circledR}$ gene expression data from over 65,000 maize gene models identified only one gene that fully exhibited strong expression in embryos and leaves, while exhibiting low expression in the ear, tassel, and tassel meristem, and with no detectable expression in roots. The promoter from this gene (a phospholipid transferase protein, $\left.Z m-P L T P_{p r o}\right)$, was then used to drive $B b m$ expression $\left(Z m-P L T P_{p r o}:: B b m\right)$. Surprisingly, when $Z m-P L T P_{p r o}:: B b m$ in combination with $N_{p o s}::$ Wus2 were transformed into immature zygotic embryos, uniformly transformed somatic embryos rapidly formed on the scutellar epithelium. These somatic embryos could be germinated directly into healthy fertile plants without any callus formation. However, the T1 seed from the transgenic plants containing $N_{\text {pro }}:$ :Wus2 had inconsistent germination. This problem was overcome by using a maize auxin-inducible promoter Zm-Axigl (Garnaat et al. 2002) to drive Wus 2 expression. Transformation of immature embryos using the combination of $Z m-P L T P_{p r o}:: B b m$ and $Z m$ Axig $1_{\text {pro }}:$ Wus 2 resulted in the rapid proliferation of somatic embryos from the scutellar epithelium. These embryos were germinated directly into fertile plants without excision of the morphogenic genes. This process is very rapid and transition stage somatic embryos were visible just $8 \mathrm{~d}$ after transformation of immature embryos, growing at approximately the same rate as their zygotic counterparts. To date, this callus-free transformation process in maize immature embryos has worked in all maize genotypes tested and is both efficient, and fast.

\section{Materials and Methods}

Plant material Three public inbred lines, Fast-Flowering Mini-Maize (FFMM line A) which flowers within 25$28 \mathrm{~d}$ after planting (see McCaw et al. 2016), B73, Mo17, and five DuPont Pioneer inbred lines were used in these experiments, including two stiff-stalk inbred lines (PHH5G and PH1V69) and three non-stiff-stalk inbred lines (PHR03, PH184C, and PH1V5T). One of the DuPont Pioneer inbred lines reported in this article (PHR03) is non-proprietary and publicly available along with B73 and Mo17 from USDA-GRIN (https://www.ars-grin.gov/). The other four DuPont Pioneer inbred lines described in this research are proprietary (PHH5G, PH1V69, PH1V5T, and PH184C). All plants used for source immature embryos were greenhouse-grown.

Agrobacterium tumefaciens strains and vectors An auxotrophic (THY-) version of A. tumefaciens strain LBA4404 containing $\mathrm{pVir} 9$, a separate accessory plasmid containing Bo542 virulence genes (Anand et al. 2017a, b, GenBank accession\# MF788073) was used for all immature embryo transformations (PHP79065, PHP79066, and PHP79094). Table 1 lists all of the molecular components (promoters, genes, $3^{\prime}$ sequences, etc.). The Axig1 promoter used in this study was modified by the addition of a single tet operator sequence (Gatz et al. 1992) placed at the transcription start site with the thought that additional repression would be necessary to obtain normal plants. This was found to be unnecessary and all future vectors were constructed without this operator and no differences in transformation or plant phenotypes were observed.

Cartoons depicting the arrangement of expression cassettes within the T-DNA of plasmids used in these experiments can be found in Fig. 1. PHP79094 contained three expression cassettes (Fig. 1A). The first cassette contained the maize PLTP promoter driving ZsGREEN (Takare Bio USA; Mountain View, CA), the second contained the maize Ubi promoter and intron driving PMI and the third contained the rice Actin promoter driving moPAT. PHP79065 contained four expression cassettes: the first contained the Nos promoter driving Wus2, the second contained the $\mathrm{Zm}$ PLTP promoter driving $B b m$, the third contained the Sorghum ALS promoter driving the maize Hra (a double mutant of the maize ALS gene that confers resistance to sulfonylureas and imidazolinones, see Green et al. 2009), and the fourth contained the barley LTP2 promoter driving ZsYELLOW (Fig. 1B). PHP79066 was identical to PHP79065 except the maize Axig1 promoter was used in place of the Nos promoter to drive Wus2 (Fig. 1C).

Some materials reported in this paper contained the selectable markers moPAT and PMI owned by Bayer Crop Science International AGb (Leverkusen, Germany) and Syngenta International AG (Basel, Switzerland), respectively (see Table 1 and references therein). Pioneer Hi-Bred International, Inc. (Johnston, IA) will provide plasmids to academic investigators for non-commercial research under an applicable material transfer agreement subject to proof of permission from any third-party owners of all or parts of the material and to governmental regulation considerations. Completion of a stewardship plan is also required. Obtaining permission from third parties will be the responsibility of the requestor. 
Table 1. Genetic components used to construct expression cassettes within the T-DNAs

\begin{tabular}{|c|c|c|c|}
\hline Component type & Label & Description & References \\
\hline \multirow[t]{7}{*}{ Promoters } & $U b i_{\text {pro }}$ & $\begin{array}{l}\text { The maize ubiquitin promoter, the } 5^{\prime} \text { UTR, } \\
\text { and the first intron }\end{array}$ & Christensen et al. (1992) \\
\hline & $S b-A L S_{\text {pro }}$ & The sorghum ALS promoter & $\begin{array}{l}\text { SB-ALS promoter and 5' UTR, } \\
\text { DOE-JGI Sbi v3.1, SBChr04, } \\
\text { bases 49239164-49240031. } \\
\text { DOE-JGI Sbi v3.1 corresponds } \\
\text { to Sorghum bicolor BTx623 } \\
\text { assembly v3.0.1 and gene } \\
\text { annotation v3.1 available from } \\
\text { phytozome (http://phytozome.jgi.doe.gov/). } \\
\text { Chromosome } 4 \text { of Sbi v3.1 is registered as } \\
\text { NCBI accessions NC_012873.2 and CM000763.3 }\end{array}$ \\
\hline & PLTP $_{\text {pro }}$ & Maize phospholipid transferase promoter & Anand et al. $(2017 \mathrm{a}, \mathrm{b}) \mathrm{US} 20170121722$ \\
\hline & LTP $2_{\text {pro }}$ & Barley lipid transferase promoter & Kalla et al. (1994) \\
\hline & $n o s_{\text {pro }}$ & The Agrobacterium-derived nopaline synthase promoter & An (1986) \\
\hline & Axig $1_{\text {pro }}$ & The maize Axig1 promoter & Garnaat et al. (2002) WO2002006499 \\
\hline & $r a b 17_{\text {pro }}$ & The maize $r a b 17$ promoter and 5' UTR & Busk et al. (1997) \\
\hline \multirow[t]{3}{*}{ 3' Sequences } & PINII & The potato proteinase inhibitor II (pinII) 3' sequence & An et al. (1989) \\
\hline & $S b-P E P C 3^{\prime}$ & $\begin{array}{l}\text { The PepCarboxylase } 3^{\prime} \text { regulatory sequence } \\
\text { from Sorghum bicolor }\end{array}$ & Anand et al. $(2017 \mathrm{a}, \mathrm{b}) \mathrm{US} 20170121722$ \\
\hline & $O s-T 283^{\prime}$ & The T28 3' regulatory sequence from Oryza sativa & Bhyri et al. (2014) US20140130205 A1 \\
\hline \multirow[t]{5}{*}{ Marker genes } & PMI & The phosphomannose isomerase gene from $E$. coli & Negrotto et al. (2000) \\
\hline & HRA & $\begin{array}{l}\text { The maize ALS double mutant gene conferring } \\
\text { herbicide resistance }\end{array}$ & Green et al. 2009 \\
\hline & moPAT & $\begin{array}{l}\text { A maize codon-optimized gene encoding } \\
\text { phosphinothricin acetyltransferase }\end{array}$ & Jayne et al. (2000) US6096947 \\
\hline & ZsYELLOW & $\begin{array}{l}\text { The ZsYellow } 1 \mathrm{~N} 1 \text { gene encoding a yellow fluorescent } \\
\text { protein from Zoanthus sp. }\end{array}$ & Matz et al. (1999) \\
\hline & ZsGREEN & $\begin{array}{l}\text { A gene encoding the ZsGREEN } \\
\text { protein from Zoanthus sp. }\end{array}$ & Matz et al. (1999) \\
\hline \multirow{2}{*}{$\begin{array}{l}\text { Maize morphogenic } \\
\text { genes }\end{array}$} & Zm-Wus2 & The maize Wuschel2 (Wus2) gene & Lowe et al. (2007) US7256322B2 \\
\hline & $\mathrm{Zm}-\mathrm{Bbm}$ & The maize Baby boom gene $(B b m)$ & Gordon-Kamm et al. (2005) WO2005075655 \\
\hline
\end{tabular}

Culture media used for transformations and plant regeneration All media recipes are described by Lowe et al. (2016). For the rapid methods described above $0.1 \mathrm{mg} \mathrm{L}^{-1}$ imazapyr (Sigma-Aldrich®; St. Louis, MO). was added to the somatic embryo maturation and germination steps.

Immature embryo isolation, $A$. tumefaciens-mediated transformation, and tissue culture Immature embryos (average length $2 \mathrm{~mm}$ isolated from greenhouse-grown plants) were transformed with PHP79094 and selected on mannose as described by Zhao et al. (2002), adapted for PMI selection (see also Reed et al. 2001). For PHP79065 and PHP79066, embryos were isolated and transformed as described by Lowe et al. (2016) but cultured differently. Briefly, transformation was performed as follows: A. tumefaciens strain LBA4404 THY- containing one of the above transformation vectors was grown overnight in the dark at $26^{\circ} \mathrm{C}$ on plates containing YP medium (Ishida et al. 1996) and colonies were collected and suspended in PHI-A700 liquid medium.
Immature embryos were mixed with $A$. tumefaciens strain LBA4404 THY- $(\mathrm{OD}=0.7$ at $550 \mathrm{~nm})$ in 700 liquid medium for $5 \mathrm{~min}$ and were then removed from the liquid and placed scutellum side up on 710I solid medium (co-cultivation medium) overnight at $21^{\circ} \mathrm{C}$ in the dark (for PHI-A700, 700, and 710I media, see Zhao et al. 2002). The following morning embryos were moved onto $605 \mathrm{~J}$ somatic embryo induction medium and cultured in dark at $28^{\circ} \mathrm{C}$. After 6-7 d on $605 \mathrm{~J}$ medium, the embryos were moved onto 2890 maturation medium containing $0.1 \mathrm{mg} \mathrm{L}^{-1}$ imazapyr. After $2 \mathrm{wk}$ on 2890 medium, embryos were moved to 13158 medium also containing imazapyr for germination and placed under GE Ecolux ${ }^{\circledR}$ (General Electric; Boston, MA) fluorescent lights $\mathrm{G}\left(60 \mu \mathrm{mol} \mathrm{m} \mathrm{s}^{-2}\right)$ with a 16 -h photoperiod at $26^{\circ} \mathrm{C}$.

Transformation frequency was defined as the number of treated immature embryos that produced imazapyr-resistant T0 plants (PHP79065 or PHP79066). Imazapyr selection was maintained during somatic embryo germination and plantlet production to preclude escapes. Once shoots and roots had 
Figure 1. T-DNA composition for vectors used in corn transformation experiments. $A$ depicts the $Z m$ -

${ }_{P L T P}{ }_{P R O}:: Z s G R E E N$ reporter construct, while $B$ and $C$ depict the arrangement of Wus2, Bbm, $\mathrm{Hra}$, and ZsYELLOW expression cassettes in PHP79065 and PHP79066
A) PHP79094
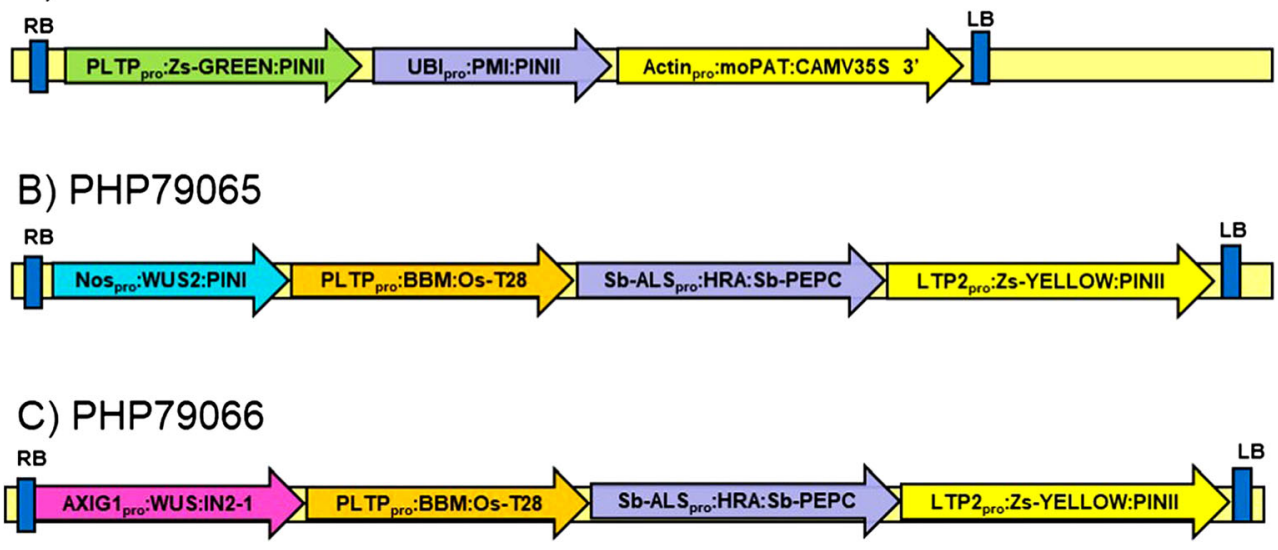

been established, plantlets were transferred to pots in a fully automated greenhouse using proprietary protocols (however, procedures for growing maize under greenhouse conditions are well established; see https://docs.lib.purdue.edu/pmcg/).

Molecular analysis All molecular analysis was done as described by Lowe et al. (2016) for polymerase chain reaction (PCR) analysis and Zastrow-Hayes et al. (2015) for Southernby-Sequencing.

Fluorescence microscopy and histology, sectioning, and microscopy Fluorescence microscopy was performed as described by Lowe et al. (2016). To further illustrate the morphology of the rapidly forming somatic embryos, zygotic embryos with protruding nascent somatic embryos were sampled at 2, 4, 6, and $7 \mathrm{~d}$ after the beginning of $A$. tumefaciens infection and fixed in $2.5 \%(v / v)$ EM-grade glutaraldehyde in $100 \mathrm{mM}$ phosphate buffer (pH 7.0) at $27^{\circ} \mathrm{C}$ with rotation at $100 \mathrm{rpm}$ (VWR Standard Orbital Shaker, Model 3500; Radnor, PA) for $4 \mathrm{~h}$. After washing with $100 \mathrm{mM}$ phosphate buffer $(\mathrm{pH}$ 7.0) three times for $15 \mathrm{~min}$ each, the samples were dehydrated in a stepwise fashion; $1-2 \mathrm{~h}$ in $70 \%(v / v) \mathrm{EtOH}, 1-2 \mathrm{~h}$ in $80 \%(v / v)$ EtOH, $1-2 \mathrm{~h}$ in $95 \%(v / v) \mathrm{EtOH}, 1-2 \mathrm{~h}$ in $100 \% \mathrm{EtOH}$, and $2 \mathrm{~h}$ in $100 \% \mathrm{EtOH}$. The tissue was then infiltrated with activated Technovit@ 7100 glycolmethacrylate (Heraeus Kulzer GMBH; Hanau, Germany), following the manufacturer's recommendation, for $2 \mathrm{~h}$, and again with refreshed activated Technovit@ 7100 overnight. The infiltrated tissue samples were placed in molds, and the Technovit@ 7100 was polymerized by the addition of $1 \mathrm{~mL}$ Hardener II into $15 \mathrm{~mL}$ of activated Technovit ${ }^{\circledR}$ 7100. The molds were placed under house vacuum of approximately $685.5 \mathrm{mmHg}$ in a vacuum desiccator chamber and allowed to polymerize overnight. Semi-thin sections of $2 \mu \mathrm{m}$ were cut with a Leica 2065 microtome (Leica Biosystems; Wetzlar, Germany), placed on drops of distilled water on glass slides and dried on a heating plate at $45^{\circ} \mathrm{C}$. Sections were stained with periodic acid-Schiff reagent (Sigma-Aldrich $®)$ according to instructions and were then counter-stained with $0.5 \%$ $(w / v)$ Naphthol blue black in $7 \%(v / v)$ acetic acid solution for $5 \mathrm{~min}$ and washed again in distilled water. The sections were then mounted in Permount ${ }^{\mathrm{TM}}$ (Thermo-Fisher Scientific $®$; Waltham, MA) with glass coverslips and observed.

\section{Results}

Survey of Illumina ${ }^{\circledR}$ RNAseq gene expression data and identification of Zm-PLTP An internal proprietary maize transcriptome atlas consisting of approximately 65,000 gene models from DuPont Pioneer's maize gene dataset sequenced was surveyed with the Illumina ${ }^{\circ}$ RNAseq protocol. The transcriptome atlas was sourced from over 500 mRNA samples including an average of four bio-replicates from most major maize tissues and developmental stages ranging from VE to V19; R1 to R5; and multiple embryo parts (leaf emerging, leaf production, and reproductive growth stages in the Growth Stage Ontology; Ritchie et al. 1986; Pujar et al. 2006). The RNA Sequencing by Expectation Maximization method (RSEM; Li and Dewey 2011) was used as the metric for the quantification of gene expression in transcripts per million reads observed normalized units (TPM) with each gene model's TPM estimate summarizing the expression value for all its measurable isoforms in a way that is relative to the total number of sequences in a particular sample's library.

In order to simplify gene expression profile scanning, the data matrix was reduced by calculating average RSEM expressions per gene for all biological replicated samples, thus reducing the dataset to about 130 tissues per development stage combinations and by filtering genes with very high variance within sets of biological replicates. Python scripts calculated a series of metrics per gene that allowed detection of expression outliers, including internal implementation of the Shannon's entropy for information content (Hs) and the Minimum Akaike's Information Criterion (MAICE, AIC) as defined in the original ROKU method and improved on by the ROKU-SPM method https://www.rdocumentation.org/ 
packages/TCC/versions/1.12.1/topics/ROKU (Kadota et al. 2003, 2006, 2007; Guo et al. 2013) and the resulting matrix loaded into TIBCO Spotfire ${ }^{\circledR} 7.0$ software (TIBCO® Software Inc.; Palo Alto, CA). The new metrics were used to filter and retain genes for which expression values across all root and root-tissue samples were effectively zero (based on outlier detection). Further filtering retained genes with overall "medium to high" stable expression values across other tissues of interest (leaf at multiple stages; embryo and subtissues) reducing the set to only 11 gene candidates. Two candidates were shortlisted for comparison of their promoter with the standard transformation $Z m-U B I$ promoter. Of these two, only Zm-PLTP had both high expression in embryo tissues and abundant matching ESTs sequenced in independent callus libraries. The expression profile for this gene and that of $Z m-U B I$ are shown in Fig. 2 for comparison.

Expression of Zm-PLTPpro::ZsGREEN in maize A 1062-bp fragment upstream of the $Z m-P L T P$ coding sequence containing the PLTP promoter and 5' UTR was synthesized by GenScript and designated herein as Zm-PLTP $P_{\text {pro }}$. Immature embryos from the maize inbred $\mathrm{PH} 184 \mathrm{C}$ were transformed with PHP79094 (Fig. 1A), a plasmid containing $Z m$ PLTP $_{\text {pro }}:$ ZsGREEN, UBI $I_{p r o}:: P M I$, and Os-Actin ${ }_{p r o}:: m o P A T$, using conventional callus transformation procedures. qPCR was used to identify single-copy plantlets and these were sent to the greenhouse for observations. ZsGREEN expression was observed in callus prior to plant regeneration (not shown) and was also observed in leaf subsidiary and cork cells in T0 plants (Fig. $3 A$ ), as well as in silks of the T0 plants (Fig. $3 B, C$ ). T1 embryos at $14 \mathrm{~d}$ after pollination (DAP) were rescued and strong ZsGREEN expression was observed in the scutellar epithelial layer after being placed on culture medium (Fig. 3D). The visual expression patterns were consistent with the Illumina ${ }^{\circledR}$ expression data.

Zm-PLTPpro::Bbm with either Nospro::Wus2 or $\mathrm{Zm}$ Axig1pro::Wus2 induced somatic embryo formation in immature zygotic embryos Immature zygotic embryos were transformed with PHP79066 (Zm-Axig $1_{\text {pro }}:: W u s 2+Z m$ -

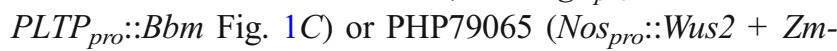
$P_{\text {PLP }}$ pro::Bbm Fig. $\left.1 B\right)$. A modified version similar to PHP79066 was constructed with (Zm-Axig $1_{p r o}:: W u s 2+Z m$ $\left.P L T P_{p r o}:: B b m+U B I_{p r o}:: Z s G R E E N\right)$ to permit visualization of fluorescence during all stages of somatic embryo development and early plantlet formation (Fig. $4 B-D$ ). After an overnight co-culture at $21^{\circ} \mathrm{C}$, the immature embryos were transferred to a cytokinin-free somatic embryo initiation medium containing $0.8 \mathrm{mg} \mathrm{L}^{-1}$ 2,4-D and $1.2 \mathrm{mg} \mathrm{L}^{-1}$ dicamba (which is an inducer of the Zm-Axigl $1_{\text {pro }}$ ). Within $4 \mathrm{~d}$, the surfaces of almost all of the zygotic embryos were covered with wellformed somatic embryos (Fig. 4A, $B$ ). The production of somatic embryos appeared to be genotype-independent. Based on ZsGREEN expression, these embryos were uniformly transformed suggesting they were of single cell origin (Fig. $4 B-D$ ). Somatic embryos were transferred to maturation medium at $7 \mathrm{~d}$ after infection (DAI) and rapidly began germinating (Fig. 4D, E). The germinating plantlets were transferred onto medium with reduced auxin levels (to promote root elongation) $1 \mathrm{wk}$ later (14 DAI) and were ready for transplanting
Figure 2. Gene expression profile for $Z m-P L T P$ and $Z m-U B I$. Values are the average gene expression across samples grouped by major tissue category (unit: parts per million sampled reads or the numerical equivalent transcripts per million). Black bars represent the $95 \%$ confidence interval around mean). All samples contained multiple bio-replicates except for pericarp and stalk

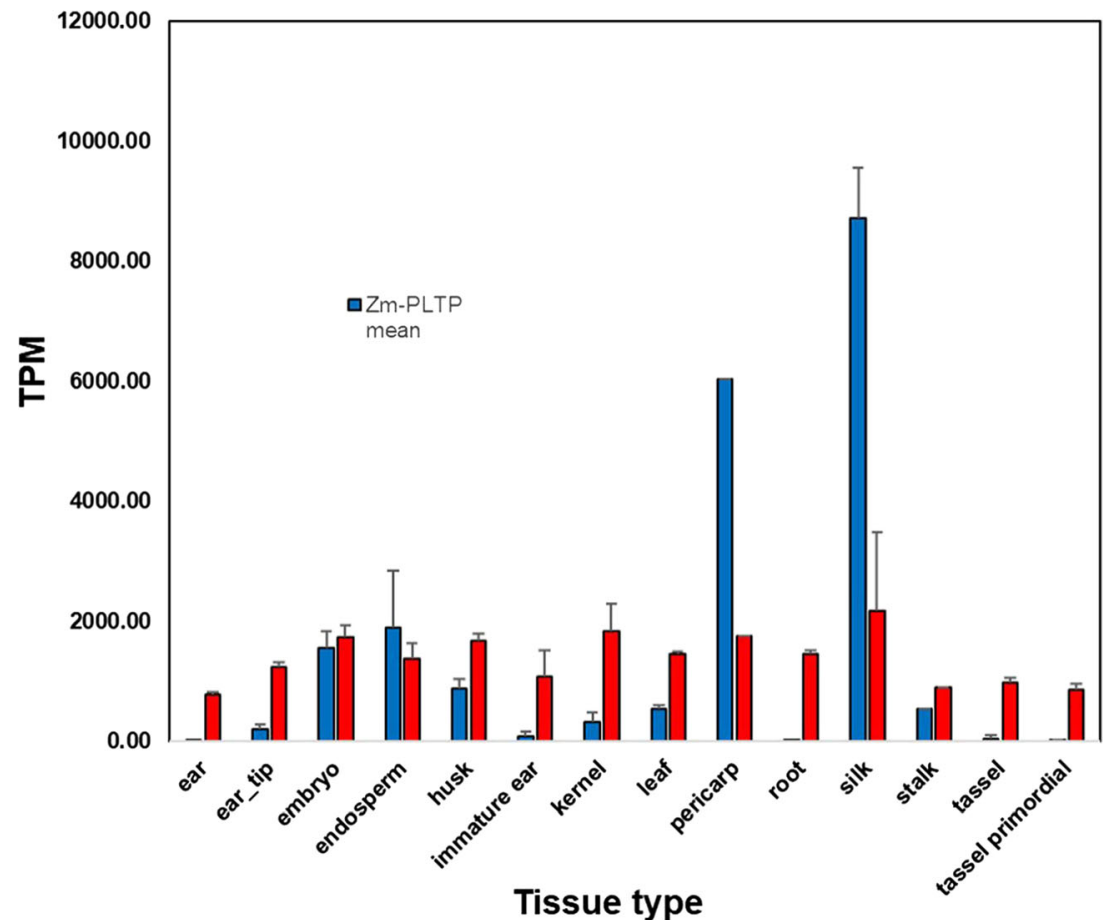


Figure 3. $Z m$ -

PLTP $_{P R O}:: Z s G R E E N$ expression

in Zea mays L. in the pairs of subsidiary cells adjacent to the guard cells, and in the small, single cork cells observed between the elongated epidermal cells in leaves $(A)$, in silk hairs $(B$ and $C$ ), and in across-section of an immature T1 embryo $(D)$
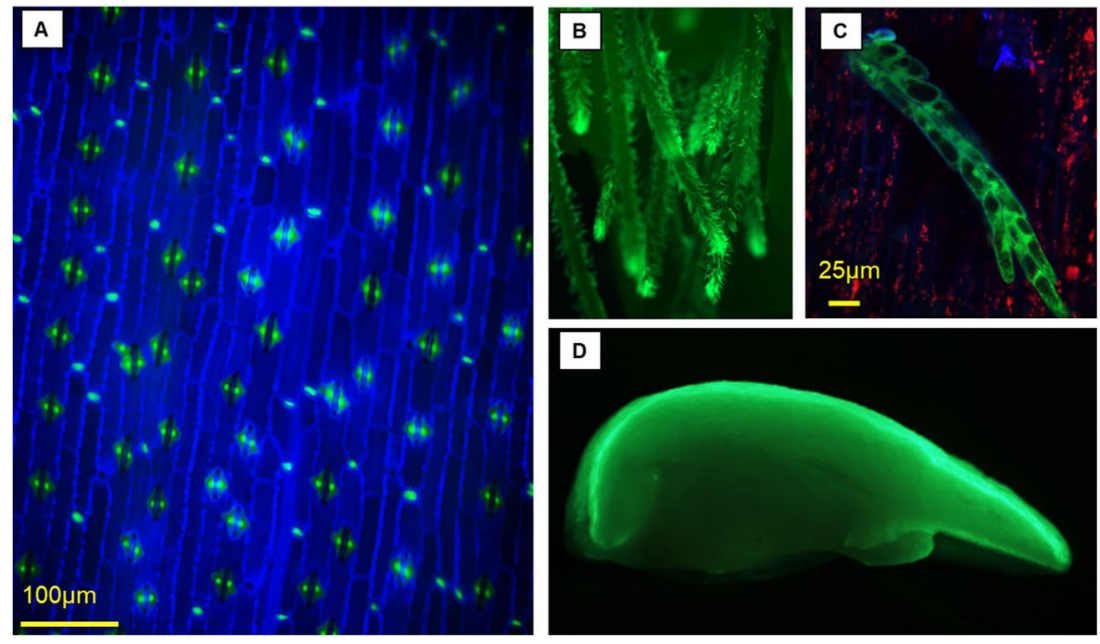

in the greenhouse within 24 DAI (Fig. 4F). Following the methods described in Lowe et al. (2016), with the modification of using a plasmid containing Zm-Axig $1_{\text {pro }}:$ Wus $2+Z m$ $\operatorname{PLTP}_{\text {pro }}:: B b m$, the rapid formation of somatic embryos in
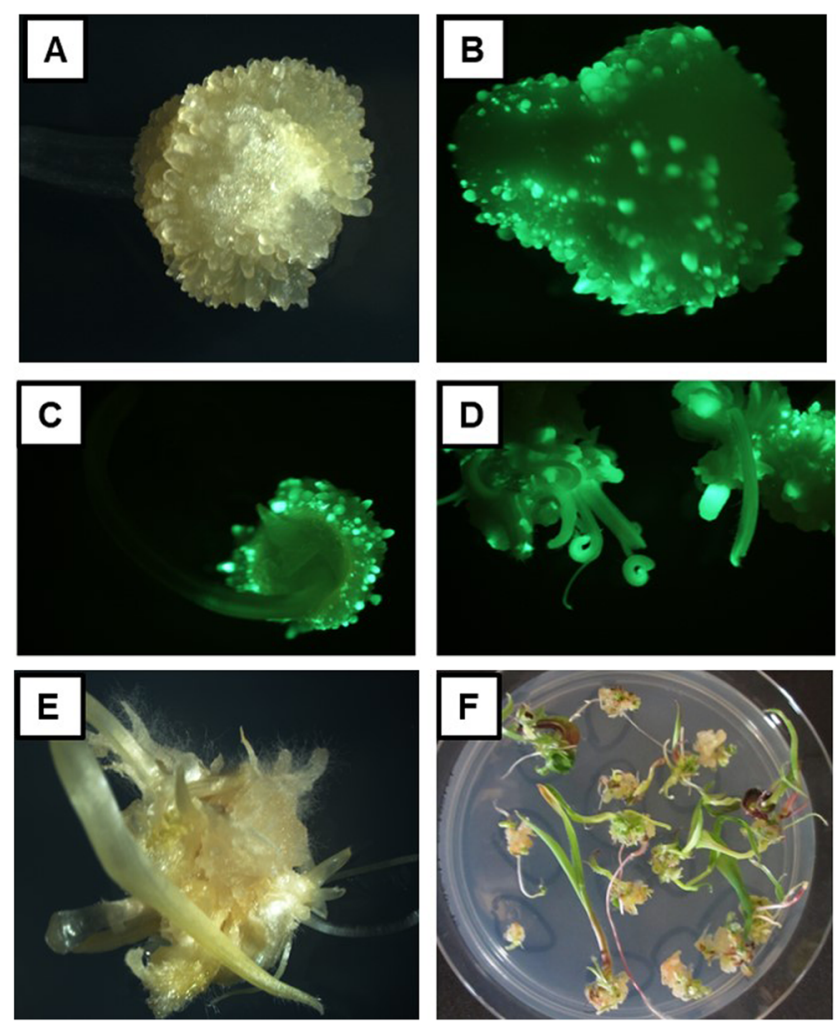

Figure 4. Rapid development of single somatic embryos of Zea may L. on the surface of recently transformed zygotic immature maize embryos shown under bright field microscopy for Fast-Flowering Mini-Maize at $7 \mathrm{~d}$ after infection $(A)$. Green fluorescence of somatic embryos at progressive durations after Agrobacterium tumefaciens infection are shown for pioneer inbred PH184C (at $4 \mathrm{~d}(B), 7 \mathrm{~d}(C)$, and $10 \mathrm{~d}(\mathrm{D})$ after infection ). $E, F$ Germinating transgenic plantlets using the public inbred Mo17 at 14 and $24 \mathrm{~d}$ (respectively) after $A$. tumefaciens infection showing 1-2 plantlets developing from each of the originally infected immature embryos alternative explants such as leaf segments or sections from mature seed was not observed. Instead, a brief intervening embryogenic callus phase was observed for 2-3 wk, followed by plant regeneration.

Anatomy of somatic embryos In order to determine the origin and ontogeny of the morphogenic gene-derived somatic embryos, zygotic embryo explants at 2, 4, 6, and 8 DAI were fixed, embedded, sectioned, and stained for light microscopy. At the stage of development that the zygotic embryos were used for transformation (approximately $2 \mathrm{~mm}$ in length), the epidermal layer facing the endosperm had differentiated into a scutellar epithelium, a layer of columnar cells that divide slowly relative to earlier stages of zygotic embryo development. These cells were the target cells for A. tumefaciens-mediated transformation. The first physiological indications of $W u s 2$ and $B b m$ expression were transverse or oblique cell divisions in scutellar epithelium cells (Fig. 5A). Occasionally, there was evidence of mitotic activity in cells immediately subjacent to the scutellar epithelium, possibly indicating a response to non-cell autonomous movement of the WUS protein from Wus 2 expressing cells (or other diffusible factors) into non-transgenic neighboring cells. The epithelial cells continued to divide (arrows in Fig. 5B) into 4-, 8-, and 16-cell clusters and eventually, by 4 DAI, globular embryos were observed, often with a short suspensor-like structure connecting the embryo to the scutellum of the original zygotic embryo (Fig. 5C). The cell division rate of the developing embryos was very high, with an estimated doubling time of approximately $8-10 \mathrm{~h}$ (Fig. 5D). At 4 DAI, the size of many somatic embryos and the number of cells in these globular embryos was very similar to those observed in 4-dold zygotic embryos by Kiesselbach (1949). The somatic embryos continued to develop into larger globular-shaped structures (Fig. 5E) and finally, by $8 \mathrm{DAI}$, they developed into embryos with a differentiated epidermal layer that had formed a scutellar notch where the shoot apical meristem would 


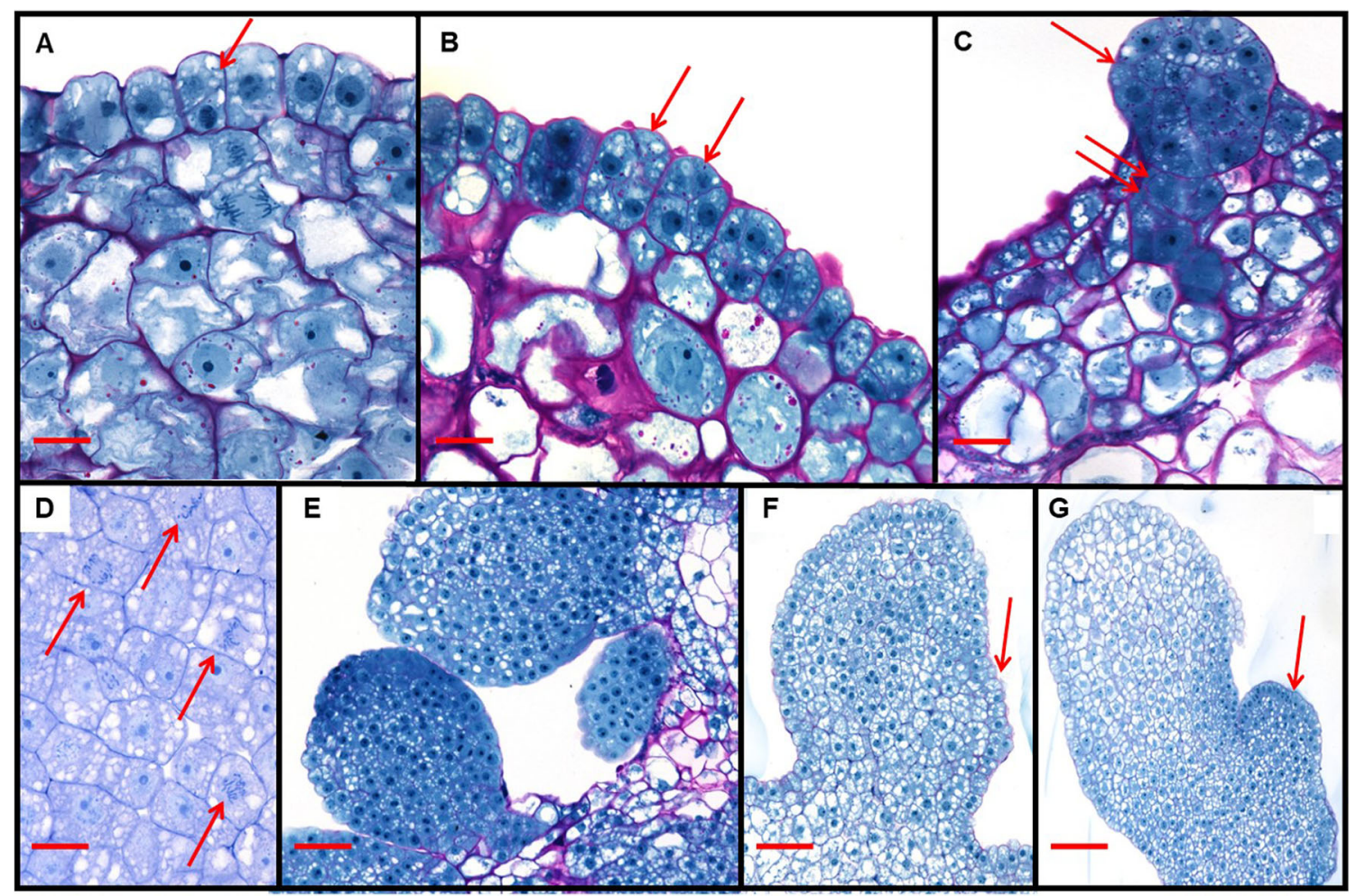

Figure 5. Histology of Zea mays L. somatic embryo development after A. tumefaciens-mediated transformation of immature embryos with a TDNA containing the expression cassettes $Z m$-Axig $1_{\text {pro }}:: W u s 2$ plus $Z m$ $P_{\text {LTP }}:: B b m$. The earliest morphological change observed were transverse or oblique cell divisions (arrow, $A$ ), continuing to divide and become multicellular (arrows, $B$ ) and growing into early globular proembryos (arrow, $C$ ) with some being subtended by what appeared to be

eventually develop (Fig. $5 F, G$ ). The somatic embryos induced by Wus 2 and $B b m$ expression were derived from single scutellar epithelial cells. Subsequent embryonic development closely recapitulated the ontogeny of maize zygotic embryos (Randolph 1936; Kiesselbach 1949) as well as rice somatic embryos derived from the scutellum epithelial layer of mature rice embryos under 2,4-D induction (Jones and Rost 1989). Somatic embryo development also resembled somatic embryogenesis from leaves as described in orchardgrass (Conger et al. 1983)

Direct germination of somatic embryos induced with $\mathrm{Zm}$ PLTPpro::Bbm and Zm-Axig1pro::Wus2 Immature embryos were transformed with PHP79066 and incubated overnight on 710 I co-cultivation medium. The next day, these embryos were moved to $605 \mathrm{~J}$ somatic embryo initiation medium and cultured in the dark for $7 \mathrm{~d}$. After $7 \mathrm{~d}$, the zygotic embryos with rapidly proliferating somatic embryos were moved to 2890 maturation medium containing $0.1 \mathrm{mg} \mathrm{L}^{-1}$ imazapyr for selection, ending the exposure to exogenous hormones (i.e., 2,4-D and dicamba) at this point. After $2 \mathrm{wk}$ on 2890 maturation medium, the zygotic embryos and attached somatic embryos were moved to 13,158 germination medium a suspensor (double arrow, $C$ ). In the developing somatic embryos, multiple mitotic figures were often observed in the same cross-section (arrows, $D$ ). In $E$, multiple independent somatic embryos were observed in close proximity, and as somatic embryos continued to develop, the embryonic meristem could be observed to develop (arrows, $F, G$ ). Scale bar: A $12 \mu \mathrm{m} ; B-D 25 \mu \mathrm{m} ; E, F 50 \mu \mathrm{m} ; G 100 \mu \mathrm{m}$

containing $0.1 \mathrm{mg} \mathrm{L}^{-1}$ imazapyr and placed under fluorescent lights. Many of the somatic embryos germinated, and after 2 $4 \mathrm{wk}$, plantlets were transplanted into flats and moved into the greenhouse. Plants were sampled for qPCR and copy number determined for Wus2, Bbm, and Hra (amplifying across the junction of the coding sequences and terminators). Events that were single copy for Wus2, Bbm, and Hra and that were also backbone negative were designated quality events.

Transformation frequencies Plant transformation frequencies [(number of T0 plants $\div$ number of starting immature embryos) $\times 100$ ] ranged from 8.7 to $96 \%$ based on the number of starting embryos (see Table 2). In a separate set of experiments, larger numbers of immature embryos from three Pioneer inbred lines (PHR03, PHH5G, and PH1V69) were transformed and copy number analysis was determined on individual plantlets (Table 3). For these three inbred lines, transformation frequencies ranged from 9.1 to $62.5 \%$.

This rapid transformation method successfully produced transgenic T0 plants in immature embryos isolated from all the ears tested (for all eight inbred lines used in the experiments summarized in Tables 2 and 3). However, transformation frequency varied between inbred lines with averages 
Table 2. Numbers of independent Zea mays L. cv. PHP79066 T0 events produced from various pioneer and public inbred lines. For each inbred, replicates are indicated in separate rows, with each row reflecting immature embryos harvested from a single ear. Transformation Frequency calculated as (number of T0 plants $\div$ number of embryos) $\times 100$

\begin{tabular}{llll}
\hline Genotype & $\begin{array}{l}\text { Number of } \\
\text { embryos }\end{array}$ & $\begin{array}{l}\text { Number of } \\
\text { T0 plants }\end{array}$ & $\begin{array}{l}\text { Transformation } \\
\text { frequency (\%) }\end{array}$ \\
\hline PHR03 & 72 & 32 & 44 \\
PHR03 & 41 & 27 & 66 \\
PHR03 & 36 & 27 & 75 \\
PHR03 & 39 & 30 & 77 \\
PH184C & 188 & 57 & 30 \\
PHH5G & 75 & 168 & 224 \\
PH1V5T & 90 & 26 & 29 \\
Mo17 & 133 & 46 & 35 \\
Mo17 & 172 & 25 & 15 \\
Mo17 & 51 & 16 & 31 \\
B73 & 36 & 18 & 50 \\
B73 & 46 & 4 & 9 \\
B73 & 61 & 8 & 13 \\
Mini-Maize “A" & 105 & 101 & 96 \\
Mini-Maize “A" & 150 & 132 & 88 \\
\hline
\end{tabular}

ranging from $9 \%$ for one ear from B73 to $224 \%$ for one ear from PHH5G (since more than one independent somatic embryo originating from a single $A$. tumefaciens-infected zygotic embryo could germinate to form T0 plants, transformation frequencies above $100 \%$ could be observed). Variability was also observed between individual ears from the same inbred (for example in B73 which produced transformation frequencies of 9,13 , and $50 \%$ for immature embryos isolated from the three ears tested). For the copy number analysis in T0 plants shown in Table 3 , if a plant was single copy for all the transgenes and with no A. tumefaciens backbone, it was considered a quality event (QE) relative to the number of $\mathrm{T} 0$ plants analyzed, while usable quality event frequencies
(UQE\%) referred to the frequencies of quality event relative to the original number of starting immature embryos and ranged from 3.64 to $12.5 \%$.

T0 and progeny analysis While all the transgenic events were confirmed by qPCR, production transformation requires higher standards and these events were further characterized to determine the site of integration and to confirm that endogenous genes were not disrupted. To demonstrate integration, Southern-by-Sequencing data ( $\mathrm{SbS}^{\mathrm{TM}}$, see Zastrow-Hayes et al. 2015) is shown for the junction region around the left border for nine events that had previously been characterized as single-copy events by qPCR (Fig. 6). All nine events had T-
Table 3. Summary data for transformation experiments for the pioneer Zea may L. inbred lines PHR03, PHH5G, and PH1V69 after transformation with a T-DNA containing $Z m-P L T P_{p r o}:: B b m$ plus either Nos $_{\text {pro }}:$ Wus2 (PHP79065) or Zm-Axig1::Wus2 (PHP79066), showing the number of immature embryos infected with Agrobacterium tumefaciens, the resulting number of $\mathrm{T} 0$ plants sampled for PCR, the transformation frequency ((number T0 plants $\div$ initial number of Embryo $) \times 100)$, the number of plants that were single copy for the transgenes (quality events based on qPCR) and the final frequency of usable quality events (single copy with no backbone relative to the original number of starting immature embryos). For each inbred, replicates are indicated in separate rows, with each row reflecting immature embryos harvested from a single ear

\begin{tabular}{|c|c|c|c|c|c|c|}
\hline Genotype & Plasmid & $\begin{array}{l}\text { Embryo } \\
\text { Number }\end{array}$ & $\begin{array}{l}\text { Number of } \\
\text { Plants } \\
\text { sampled }\end{array}$ & $\begin{array}{l}\text { Transformation } \\
\text { Frequency }(\%)\end{array}$ & $\begin{array}{l}\text { Plant } \\
\text { QE } \\
\text { Number }\end{array}$ & $\% \mathrm{UQE}$ \\
\hline PHR03 & 79065 & 210 & 60 & 28.6 & 10 & 4.8 \\
\hline PHR03 & 79066 & 200 & 125 & 62.5 & 25 & 12.5 \\
\hline PHH5G & 79065 & 162 & 41 & 25.3 & 11 & 6.8 \\
\hline PHH5G & 79066 & 165 & 15 & 9.1 & 6 & 3.7 \\
\hline PH1V69 & 79065 & 148 & 37 & 25 & 9 & 6 \\
\hline PH1V69 & 79066 & 155 & 47 & 30.3 & 14 & 9 \\
\hline
\end{tabular}




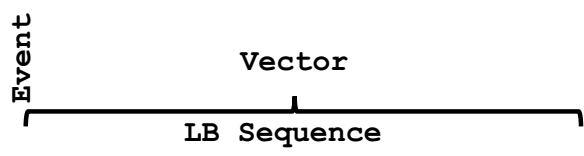

XXXXXXXXGTTACACCACAATATATCCTGCCA

1 XXXXXXXXTTTCCGCGCCCCGCAGGCCGCAGCATTCGACCCCACACGCCTAGCCGCCGCCGCAGCCGACGCAGGCCATCCCGACTCCGCCCG Chr. 10

2 XXXXXXXXTTTACACCACAATATATCCTGGACCAGCTGGAAGAGGCTCGGGACAAGGCCTTACTACACTCGGCGCGGTACCAGCAGTCCCTG ?

3 XXXXXXXXGTTTACACCACAATACTACTTGTCCTGCAGCTATCTTAAGTCGCTGCACTTCTTCCCGCAGGGTTTCGTTCAAAGCTGTGTGAGG Chr. 3

4 XXXXXXXXGTTACACCACGATGAAGTCACTTCCTAAACCGCCACGTCCCACAAAGGACGCCACACGGCACCCTAATCCCGACGGCTTACGTA Chr. 9

5 XXXXXXXXGATGGACGACATCCATGGGTGGGGAGTTCTCTTCGACGACAAAGTTGGGGATGGAACCGTCTCTGTAAGTGCACAAGATCCACAC Chr. 8

6 XXXXXXXXTTTACACCACAATATATCCTACAGGCATCTAAAAACCCATGCAACTGCGACTGCAACGCTACCGGGTGAAAAAATGCCCCCCCC ?

7 XXXXXXXXGTTACACCACAACCATGCAGATATGAAAAAGCATGAGGGGCTAGACTCACCATAAAGCTAGCTCAAGATCCCAGAAACCCATGT Chr. 2

8 XXXXXXXXGTCACGTGCCCGGCTCGGCGATGCTCTCTCACTCGTCCCACGCAGAGCCAACTACCCAACCCACGCAGGTCAGCGGGGCGGGTG Chr. 5

9 XXXXXXXXTTTACACCACAATATATTGAGTGCAACCCTCGTCCGTTGGGACGCCACAACATGGAGTAGGCAAGTATTGGACTTGGCCGAACC ?

Figure 6. $\mathrm{SbS}^{\mathrm{TM}}$ data from nine single copy Zea mays L. events produced in inbred PHR03 showing the flanking sequences between the left border (yellow) and chromosomal DNA. Chromosome assignments are based on

DNA flanking regions that mapped to the B73 genome build and each of the two flanking genomic sequences (two per event) mapped to the same chromosomal location.

T1 progeny segregation was evaluated using qPCR for the cassette components in the T-DNA to determine zygosity in T1 seedlings from four self-pollinated PH1V5T T0 plants and two self-pollinated PHR03 T0 plants. For all six plants that were self-pollinated, the progeny segregated as expected based on chi-square analysis using a 95\% confidence level (Table 4).

Physical separation of somatic embryos resulted in increased plantlet formation Early observations clearly showed high numbers of somatic embryos that started to grow on the scutellum of each A. tumefaciens-infected zygotic embryo (see Fig. $3 A-D$ ). However, as these somatic embryos continued to develop and germinate, typically only 1-2 plantlets would develop robustly from the scutellar surface of the originally transformed zygotic embryo (see Fig. $4 E, F$ ). This suggested that embryo competition between these crowded embryos might be occurring, so the separation of these small developing somatic embryos was attempted to evaluate their subsequent development.
B73 models which may not be representative of this inbred. In some cases, the T-DNA insertion integrated into a repetitive region and chromosome location could not be accurately assigned

To test whether this suspected somatic embryo competition could be mitigated, the population of somatic embryos growing on 45 originally infected immature embryos from inbred PHH5G were collected after 2 wk on maturation medium and vortexed in liquid medium to separate the somatic embryos. The maturing somatic embryos were then re-plated onto germination medium. This resulted in over 380 plants being recovered from the originally transformed 45 starting embryos. qPCR analysis of a subset of 152 individual plantlets indicated that the individual analyzed plantlets were not clonal but instead were independent transgenic events, and of the 152 analyzed, 48 were identified as single copy plants resulting in a UQE\% of greater than $100 \%$ (Fig. 7).

Plant morphology and fertility Transgenic T0 plants containing a single copy of the T-DNA from PHP79066 were grown to fertility in the greenhouse. These plants were indistinguishable from wild-type inbred plants and were fully both male and female fertile. Segregating T1 progeny from these plants had moderate to high germination rates with uniform robust morphology. In some events, homozygous plants were slightly shorter in stature than nulls but fully fertile, suggesting that
Table 4. Progeny analysis from self-pollinated Zea mays L. T0 events. Representative seed set and progeny data for selfpollinated single copy T0's transformed with PHP79066 are shown

\begin{tabular}{|c|c|c|c|c|c|c|c|}
\hline \multirow[b]{2}{*}{ Genotype } & \multirow[b]{2}{*}{ Event } & \multirow[b]{2}{*}{$\begin{array}{l}\text { T0 } \\
\text { seed set }\end{array}$} & \multicolumn{5}{|c|}{ Progeny analysis } \\
\hline & & & $\begin{array}{l}\text { Number of } \\
\text { seeds sowed }\end{array}$ & $\begin{array}{l}\text { Number of seeds } \\
\text { germinated }\end{array}$ & $\begin{array}{l}\text { Number } \\
\text { homozygous }\end{array}$ & $\begin{array}{l}\text { Number } \\
\text { hemizygous }\end{array}$ & $\begin{array}{l}\text { Number } \\
\text { null }\end{array}$ \\
\hline PH1V5T & 1 & 264 & 32 & 32 & 7 & 16 & 9 \\
\hline PH1V5T & 2 & 70 & 32 & 25 & 8 & 12 & 5 \\
\hline PH1V5T & 3 & 336 & 32 & 29 & 5 & 17 & 7 \\
\hline PH1V5T & 4 & 43 & 32 & 22 & 4 & 10 & 8 \\
\hline PHR03 & 1 & 335 & 32 & 26 & 8 & 12 & 6 \\
\hline PHR03 & 2 & 244 & 32 & 30 & 8 & 17 & 5 \\
\hline
\end{tabular}



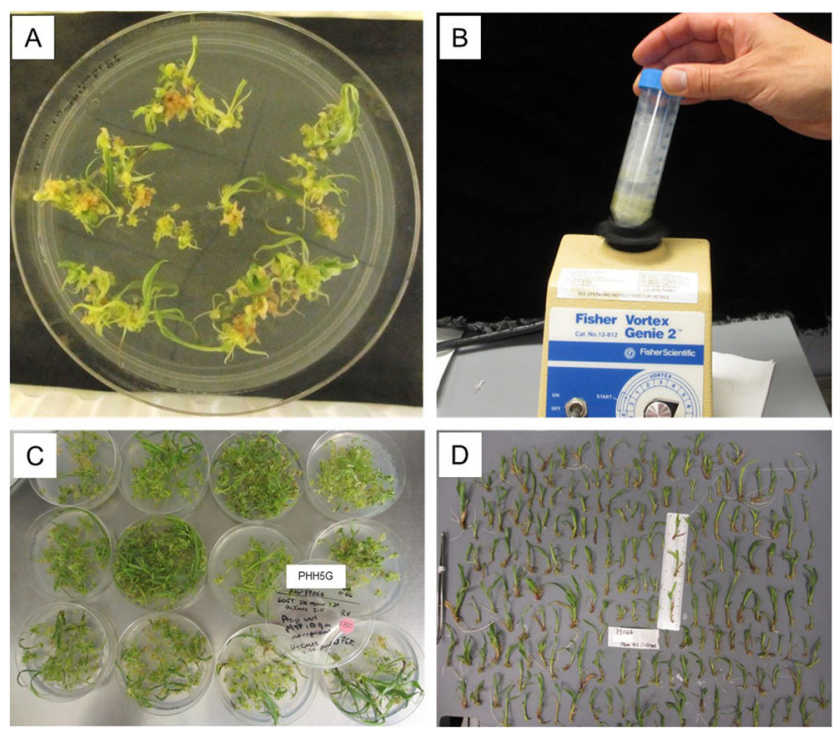

Figure 7. Using vortexing to separate germinating Zea mays L. somatic embryos. At $20 \mathrm{~d}$ post Agrobacterium tumefaciens infection, all the developing tissue $(A)$ was transferred to liquid and vortexed $(B)$. The tissue was distributed back onto germination medium. The number of recovered $\mathrm{T} 0$ plantlets was high $(C)$ and from a total of 45 originally transformed zygotic embryos, a total of over 380 independent transgenic plantlets were recovered $(D)$

some pleiotropy might still have been occurring. While singlecopy plants were phenotypically normal, abnormal plants from multicopy events derived from particle gun transformations have also been observed.

\section{Discussion}

Lowe et al. (2016) previously demonstrated that the maize morphogenic regulators $\mathrm{Bbm}$ and Wus2 can be used to stimulate growth of embryogenic callus from immature embryos and normally recalcitrant tissues such as leaves or explants derived from mature seeds. Constitutive expression of $\mathrm{Bbm}$ and Wus 2 has severe pleiotropic effects such as wrinkled leaves (WUS, see Lenhard et al. 2002), sterility, and poorly functioning, thickened roots (Boutelier et al. 2002). To avoid these problems, an efficient excision system using LoxP sites and desiccation-induced CRE excision was developed (Lowe et al. 2016). As an alternative to CRE-mediated excision, a search to identify regulatory elements that would limit expression to transformation targets, specifically, scutella, and young leaves was undertaken. By eliminating expression in roots, meristems, and reproductive tissue, it was hypothesized that controlled expression could allow for the development of more normal plants while enhancing transformation in alternative targets such as mature seeds.

It was also hypothesized that by restricting expression to normally regenerable tissues, the transformation process would be enhanced by limiting the growth stimulation of the morphogenic genes to pluripotent cells. Since $B b m$ expression causes root abnormalities, a search for promoters that were not expressed in roots was undertaken. Furthermore, since in previous methods, cultures progressed through a process of embryogenic callus formation, it would be desirable for expression of $B b m$ to also occur in embryos and embryogenic callus. Expression in young leaves is also desirable since leaf primordia from mature seeds were demonstrated to have good transformation potential (Lowe et al. 2016). For that reason, a genome wide search was undertaken to find candidate promoters to drive this specific pattern of expression. Based on the desired selection criteria, promoters for these genes were cloned and evaluated. From a survey of over 65,000 gene models in a proprietary database, only one gene, a phospholipid transferase protein gene $(Z m-P L T P)$ met the criteria perfectly. In addition, the non-Illumina®-derived ESTs for this gene were from libraries prepared from either zygotic embryos or from embryogenic callus, confirming the desired expression pattern. $Z m-P L T P_{\text {pro }}$ was chosen to drive $B b m$ expression for two reasons. First, as described above, it was desired to prevent the expression of $\mathrm{Bbm}$ in root tissues, and second, such expression patterns might represent a viable alternative to excising Bbm and Wus2 in order to avoid deleterious pleiotropic effects in maize roots and reproductive structures, often leading to either lethality or sterility.

Expression levels for both the Ubiquitin and PLTP transcripts were similar based on RNA obtained from whole embryo extracts (Fig. 2). However, since the $\mathrm{Zm}$ $P_{\text {PLTP }}:: Z_{s} G R E E N$ expression was confined to the outer layers of the scutellum (Fig. 3D), it is likely that PLTP expression was much higher than Ubiquitin in the localized region of the scutellum epithelial layer. Expression of ZsGREEN from rescued $Z m-P L T P_{p r o}:: Z s G R E E N$ embryos increased after placement on culture medium suggesting that culture stress also increased expression but was later down regulated once embryo fate was established. This is consistent with data demonstrating that PLTP expression was elevated under drought and cold stress conditions. Transcript profiling of developing somatic embryos showed very weak expression of PLTP transcripts during early stages of embryo development (data not shown), but at later stages of embryo development expression was stronger (Fig. 2).

The first vectors with the new PLTP promoter driving expression of $B b m$ were not only designed to test the impact of this expression cassette on transformation frequencies but also to assess later pleiotropic effects on plant development (i.e., with no recombinase-mediated excision before germination). When immature embryos were transformed with $\mathrm{Zm}$ $P_{C T P}{ }_{p r o}:: B b m$, the transgenic response was both rapid and consistent. After A. tumefaciens infection with this expression cassette in combination with either an Zm-Axig $1_{p r o}:: W u s 2$ or $N_{\text {Nos }}$ pro: $:$ Wus 2 cassette, somatic embryos could be observed just $2 \mathrm{~d}$ later arising from the scutellar epithelia layer. This 
response was auxin-dependent which is consistent with auxins almost always being required for the initiation of embryogenic cultures in maize (Samaj et al. 2003) and embryogenic cultures in general (Zimmerman 1993; von Arnold et al. 2002). Without auxins, the immature zygotic embryo explants immediately germinate, and no somatic embryos are formed. Close to $100 \%$ of the infected embryos were covered with these somatic embryos and this response appeared to be genotypeindependent. To date, this method has been tested in more than 22 of Pioneer's current production inbred lines as well as the public inbred lines B73, Mo17, and FFMM line A (McCaw et al. 2016) and all have been responsive. These early somatic embryos were well formed and similar in appearance to those observed in Dactylis (Conger et al. 1983) and Oryza (Jones and Rost, 1989).

The rapid de novo somatic embryo development observed within the first week closely recapitulated zygotic embryo development as described by Kiesselbach (1949). Analogous to zygotic embryos, the somatic embryos observed grew rapidly and mitotic figures were readily observed in cross-section. Embryos containing approximately $750-800$ cells were observed within $4 \mathrm{~d}$ of $A$. tumefaciens infection, again emulating the 4-d-old zygotic embryos observed by Kiesselback (1949). After $7 \mathrm{~d}$, the somatic embryo development became more aberrant and typical of previous description by Van Lammeren (1988) of somatic embryos in maize, who also observed rescued zygotic embryos developing abnormally when placed in culture, possibly due to the lack of physical restraints during growth.

Single transformed immature zygotic embryos often produced dozens of somatic embryos on the surface of the scutellum. However, only a fraction of these somatic embryos ultimately germinated (compare the number of fluorescent embryos in Fig. $4 B-C$ with the number of plants produced from each of the originally transformed immature embryos in Fig. 4F). Part of this attrition could be due to the fact that no effort was taken to orientate these somatic embryos on the culture medium. Matthys-Rochon et al. (1998) found that embryo germination was greatly improved when the developing meristem was not in contact with the culture medium after the transition stage. Competition between developing embryos presents another possible explanation for somatic embryo attrition during development and germination. In some genotypes, such as PHH5G, the somatic embryos are loosely connected and can be easily separated early in development, resulting in much higher numbers of recovered individual transgenic plants. This observation suggested that somatic embryo attrition may be influenced by competition or inhibition by unknown factors. Similarly, when polyembryony occurs in nature it is common to have single dominant embryos (Filonova et al. 2002).

It appears that these somatic embryos are of single cell origin for the following reasons. First, evidence that favored a single cell origin include (i) early somatic embryos that formed on the surface of the scutellum uniformly expressed fluorescent proteins and were separated by non-fluorescing zygotic scutellar surface (Fig. 4C), (ii) chimeric plants were not observed, and (iii) for individual transgenic plants analyzed by $\mathrm{SbS}^{\mathrm{TM}}$, the junctions between the integrated TDNA and the genome were unique for every plant (Fig. 6). Secondly, observations that were consistent with a single cell origin for the somatic embryos include (i) microscopy suggested single cell origin based on the fact that individual early embryos were only observed growing from the zygotic scutellar surface, (ii) the growth of embryos was rapidly induced by the morphogenic genes and the T-DNA was delivered into single cells, and (iii) unlike during organogenesis, the embryos were never connected to the underlying tissue via vascular connections.

Embryo development and germination continued at a rapid pace and using these new expression constructs transgenic plants were obtained from many inbred lines in just 24$30 \mathrm{~d}$. This is roughly the same time it takes to obtain plants from rescued zygotic embryos. Using this method, plants can be sent to the greenhouse in less than half the time of the traditional process. Using these simple non-excision vectors, transgenic $\mathrm{T} 0$ plants were routinely recovered at frequencies ranging between 9 and 224\%, which varied between inbred lines and between batches of immature embryos from separate ears for the same inbred (transformation frequencies in Tables 2 and 3). Variability in transformation results between genetic backgrounds (i.e., different inbred lines or different varieties in other crops) has historically been a common observation in the field of plant biotechnology, and while this new method has worked in all the maize inbred lines tested to date, the influence of genetic background on the transformation process has not been eliminated. In addition, this method has not eliminated the ear-to-ear variability that is typically observed even within the same maize inbred where plants have been grown side-by-side in the greenhouse. This has typically been attributed to some physiological difference in the plants, but more specific information has remained elusive.

By comparison, traditional callus-based transformation protocols are labor-intensive and calluses must be bulked up for many weeks prior to regeneration and maintained long enough with selective pressure to eliminate escapes. During this prolonged selection period, care must be taken to preserve event identity with calluses derived from individual zygotic embryos maintained on separate plates to insure event purity. In contrast, with this new callus-free method, every plant was a separate event and numerous events were maintained on a single plate without the need for physical separation of events.

While $Z m-P L T P_{p r o}:: B b m$ can be used with either Nos $_{p r o}:: W u s 2$ or Zm-Axig $1_{p r o}:: W u s 2$ to induce rapid somatic embryos, from previous experiments $\mathrm{T} 1$ seed containing 
Nos::Wus2 have germination problems. These germination problems can be overcome by using the maize auxininducible $Z m-A x i g 1_{\text {pro }}$ to drive expression of Wus2, again alleviating the need for gene excision. Surprisingly, by using the Zm-PLTP ${ }_{\text {pro }}$ and restricting $B b m$ expression to silks, leaf cork, and leaf subsidiary cells the plants were indistinguishable from wild-type inbred plants and were both male and female fertile. Thus using the combination of Zm-Axig $1_{\text {pro }}:: W u s 2$ with $Z m-P L T P_{\text {pro }}:: B b m$ normal plants were recovered without excision.

Using imazapyr selection with the double mutant $\mathrm{Hra}$ gene, it was found that all the plants that regenerated on selection were transformed. Surprisingly, other traditional maize selective agents such as bialaphos (for the moPAT gene) and mannose (for the $P M I$ gene) work poorly leading to a high percentage of escapes. Possibly conventional callus tolerates a slow kill during selection. In contrast, direct embryo formation requires a more stringent, fast-acting selection due to the rapid rate of cell division and direct germination. Compared to conventional callus-based selection in maize, the formation of single somatic embryos that rapidly produce plants presents new challenges for selection of transgenic events and further development of these methods is required.

The ability to provide fertile plants without excision has significant implications for genome editing. Since edits are not linked to the integration of the morphogenic genes, segregation can be used to separate the edits from the transgenes in the following generation, minimizing the importance of obtaining single-copy transformants. However, presently, routine screening for copy number is done and only single-copy plants are sent to the greenhouse. It is possible and likely that high copy number will have an effect on plant phenotype and fertility.

All transformation experiments were performed using a ternary vector system recently described by Anand et al. $(2017 \mathrm{a}, \mathrm{b})$. The transformation results are facilitated by the A. tumefaciens strain and the presence of an accessory plasmid pPHP71539 (GenBank accession\# MF788073). The results presented here utilized an auxotrophic LBA4404 THY- harboring the accessory plasmid and the binary plasmid containing an extra set of virulence genes from Bo542 (VirB1-E3). This is the preferred combination of A. tumefaciens and accessory plasmid for this method.

\section{Conclusions}

The method described here is believed to be genotype-independent, fast, and simple. Provided one has access to a source of immature embryos, this method should enable any laboratory with tissue culture expertise to produce transgenic maize plants from any genotype. Using variations of this method (using the same basic components in different configurations and delivery methods), DuPont Pioneer has produced tens of thousands of independently transformed plants. Currently, variations of this method are being used for CRISPR/CAS9 genome editing and these methods have worked in every genotype tested to date (currently 22 pioneer and three public inbred lines). The true test of genotype independence will require testing in other labs with access to unique germplasm.

Open Access This article is distributed under the terms of the Creative Commons Attribution 4.0 International License (http:// creativecommons.org/licenses/by/4.0/), which permits unrestricted use, distribution, and reproduction in any medium, provided you give appropriate credit to the original author(s) and the source, provide a link to the Creative Commons license, and indicate if changes were made.

\section{References}

An G (1986) Development of plant promoter expression vectors and their use for analysis of differential activity of nopaline synthase promoter in transformed tobacco cells. Plant Physiol 81:86-91

An G, Mitra A, Choi HK, Costa MA, An K, Thornburg RW, Ryan CA (1989) Functional analysis of the 3' control region of the potato wound-inducible proteinase inhibitor II gene. Plant Cell 1:115-22

Anand A, Arling M, Da Silva A, Gordon-Kamm WJ, Hastings CE, Hoerster GM, Klein TM, La Rota CM, Lowe KS, Tiwari SB, Wang N, Wu XE (2017a) Methods and compositions for rapid plant transformation. Patent Number US20170121722A1

Anand A, Bass SH, Cho H-J, Klein TM, Lassner M, McBride KE (2017b) Methods and compositions of improved plant transformation. Patent Number WO 2017/078836

Boutelier K, Offringa R, Sharma VK, Keift H, Ouellet T, Zhang L, Hattori J, Liu C-M, Lammeren AMM, Miki BLA, Custers JBM, van Lookeren Campagne MM (2002) Ectopic expression of baby boom triggers a conversion from vegetative to embryonic growth. Plant Cell 14:1737-1749

Bhyri P, Khrishnamurthy N, Narayanan E, Nott A, Sarangi RR (2014) Novel plant terminator sequences. Patent Number US2014/0130205

Busk PK, Jensen AB, Pagès M (1997) Regulatory elements in vivo in the promoter of the abscisic acid responsive gene rabl7 from maize. Plant J 11:1285-1295

Christensen AH, Sharrock RA, Quail PH (1992) Maize polyubiquitin genes: structure, thermal perturbation of expression and transcript splicing, and promoter activity following transfer to protoplasts by electroporation. Plant Mol Biol 18:675-689

Conger BV, Hanning GE, Gray DJ, McDaniel JK (1983) Direct embryogenesis from mesophyll cells of Orchardgrass. Science 221:850-851

Filonova LH, von Arnold S, Daniel G, Bozhkov PV (2002) Programmed cell death eliminates all but one embryo in a polyembryonic plant seed. Cell Death Diff 9:1057-1062

Garnaat C, Lowe K, Roth B (2002) Zm-AXIG1-specific polynucleotides and methods of use. Patent Number WO2002006499

Gatz C, Frohberg C, Wendenburg R (1992) Stringent repression and homogeneous de-repression by tetracycline of a modified CaMV $35 \mathrm{~S}$ promoter in intact transgenic tobacco plants. Plant J 2:397-404

Gordon-Kamm WJ, Helentjaris TG, Lowe KS, Shen B, Tarczynski MC, Zheng P (2005) Ap2 domain transcription factor Odp2 (ovule development protein 2) and methods of use. Patent Number WO2005075655

Green CE, Phillips RL (1975) Plant regeneration from tissue cultures of maize. Crop Sci 15:417-421 
Green JM, Hale T, Pagano MA, Andreassi JL II, Gutteridge SA (2009) Response of 98140 corn with gat4621 and hra transgenes to glyphosate and ALS-inhibiting herbicides. Weed Sci 57:142-148

Guo J, Hammar M, Öberg L, Padmanabhuni SS, Bjäreland M, Dalevi D (2013) Combining evidence of preferential gene-tissue relationships from multiple sources. PLoS One 8(8):e70568. https://doi.org/10. 1371/journal.pone.0070568

Ishida Y, Satto H, Ohta S, Hiei Y, Komari T, Kumashiro T (1996) High efficiency transformation of maize (Zea mays L.) mediated by Agrobacterium tumefaciens. Nat Biotechnol 14:745-750

Ishida Y, Hiei Y, Komari T (2007) Agrobacterium-mediated transformation of maize. Nature protoc 2:1614-1621

Jayne S, Barbour E, Meyer T (2000) Methods for improving transformation efficiency Patent Number US6096947

Ji Q, Xu X, Wang K (2013) Genetic transformation of major cereal crops. Int J Dev Biol 57:495-508

Jones TJ, Rost TL (1989) The developmental anatomy and ultrastructure of somatic embryos from rice (Oryza sativa L.) scutellum epithelial cells. Bot Gaz 150:41-49

Kadota K, Konishi T, Shimizu K (2007) Evaluation of two outlierdetection-based methods for detecting tissue-selective genes from microarray data. Gene Regul Syst Bio 1:9-15

Kadota K, Nishimura SI, Bono H, Nakamura S, Hayashizaki Y, Okazaki Y, Takahashi K (2003) Detection of genes with tissue-specific expression patterns using Akaike's information criterion (AIC) procedure. Physiol Genomics 12:251-259

Kadota K, Ye J, Nakai Y, Terada T, Shimizu K (2006) ROKU: a novel method for identification of tissue-specific genes. BMC Bioinformatics 7:294

Kalla R, Shimamoto K, Potter R, Nielsen PS (1994) The promoter of the barley aleurone-specific gene encoding a putative $7 \mathrm{kDa}$ lipid transfer protein confers aleurone cell-specific expression in transgenic rice. Plant J 6:849-860

Kiesselbach TA (1949) The structure and reproduction of corn. University of Nebraska, Lincoln

Lenhard M, Jurgens G, Laux T (2002) The WUSCHEL and SHOOTMERISTEMLESS genes fulfil complementary roles in Arabidopsis shoot meristem regulation. Development 129:3195-3206

Li B, Dewey CN (2011) RSEM: accurate transcript quantification from RNA-Seq1 data with or without a reference genome. BMC Bioinformatics 12:323

Lowe KS, Cahoon RE, Scelonge CJ, Tao Y, Gordon-Kamm WJ, Bruce WB, Newman LJ (2007) Wuschel (WUS) gene homologs. Patent Number US7256322B2

Lowe K, Wu E, Wang N, Hoerster G, Hastings C, Cho M-J, Scelonge C, Lenderts B, Chamberlin M, Cushatt J, Wang L, Ryan L, Khan T, Chow-Yiu JJ, Hua W, Yu M, Bahn J, Bao Z, Brink K, Igo E, Rudrappa B, Shamseer PM, Bruce W, Newman L, Shen B, Zheng P, Bidney D, Falco C, Register J, Zhao Z-Y, Xu D, Jones T, GordonKamm W (2016) Morphogenic regulators Baby boom and Wuschel improve monocot transformation. Plant Cell 28:1998-2015
Matthys-Rochon E, Piola F, Le Deunff E, Mol R, Dumas C (1998) In vitro development of maize immature embryos: a tool for embryogenesis analysis. J Exp Bot 49:839-845

Matz MV, Fradkov AF, Labas YA, Savitsky AP, Zaraisky AG, Markelov ML, Lukyanov SA (1999) Fluorescent proteins from nonbioluminescent Anthozoa species. Nature Biotech 17:969-973

McCaw ME, Wallace JG, Albert PS, Buckler ES, Birchler JA (2016) Fastflowering mini-maize: seed to seed in 60 days. Genetics 204:35-42

Negrotto D, Jolley M, Beer S, Wenck AR, Hansen G (2000) The use of phosphomannose-isomerase as a selectable marker to recover transgenic maize plants (Zea mays L.) via Agrobacterium transformation. Plant Cell Rep 19:798-803

Pujar A, Jaiswal P, Kellogg EA, Ilic K, Vincent L, Avraham S, McCouch S (2006) Whole-plant growth stage ontology for angiosperms and its application in plant biology. Plant Physiol 142:414-428. https://doi. org/10.1104/pp.106.085720

Randolph LF (1936) Developmental morphology of the caryopsis of maize. J Agric Res 53:881-916

Reed J, Privalle L, Powell ML, Meghji M, Dawson J, Dunder E, Suttie J, Wenck A, Launis K, Kramer C, Chang Y-F, Hansen G, Wright M (2001) Phosphomannose isomerase: an efficient selectable marker for plant transformation. In Vitro Cell Dev Biol-Plant 37:127-132

Ritchie SW, Hanway JJ, Benson GO (1986) How a corn plant develops. CES Special Report No. 48. Iowa State University, Ames, IA

Samaj J, Baluska F, Pretova A, Volkman D (2003) Auxin deprivation induces a developmental switch in maize somatic embryogenesis involving redistribution of microtubules and actin filaments from endoplasmic to cortical cytoskeletal arrays. Plant Cell Rep 21: 940-945

Van Lammeren AAM (1988) Observations on the structural development of immature maize embryos (Zea mays L.) during in vitro culture in the presence or absence of 2,4-D. Acta Bot Neerl 37:49-61

Von Arnold S, Sabala I, Bozhkov P, Dyachok J, Filonova L (2002) Developmental pathways of somatic embryogenesis. Plant Cell Tissue Organ Cult 69:233-249

Wang K (2005) Maize genetic transformation: Agrobacterium-mediated. In: Plant Transformation Facility. http://ptf.agron.iastate.edu/ service/agromaize.aspx

Wang K, Frame B, Ishida Y, Komari T (2009) Maize transformation. In: Bennetzen K, hake S (eds) Handbook of maize. Genetics and genomics. New York: Springer Science + Business Media, pp. 609-639

Zastrow-Hayes GM, Lin H, Sigmund AL, Hoffman JL, Alarcon CM, Hayes KR, Richmond TA, Jedeloh JA, May GD, Beatty MK (2015) Southern-by-sequencing: a robust screening approach for molecular characterization of genetically modified crops. Plant Genome 8. https://doi.org/10.3835/plantgenome2014.08.0037

Zhao Z-Y, Gu W, Cai T, Tagliani L, Hondred D, Bond D, Schroeder S, Rudert M, Pierce D (2002) High throughput genetic transformation mediated by Agrobacterium tumefaciens in maize. Mol Breed 8: 323-333

Zimmerman JL (1993) Somatic embryogenesis: a model for early development in higher plants. Plant Cell 5:1411-1423 